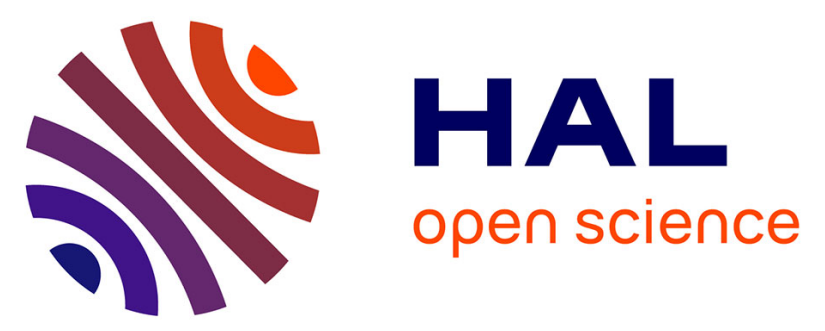

\title{
Elevated temperature and deposited sediment jointly affect early life history traits in southernmost Arctic char populations
}

Lisandrina Mari, Martin Daufresne, Jean Guillard, Guillaume Evanno, Emilien Lasne

\section{To cite this version:}

Lisandrina Mari, Martin Daufresne, Jean Guillard, Guillaume Evanno, Emilien Lasne. Elevated temperature and deposited sediment jointly affect early life history traits in southernmost Arctic char populations. Canadian Journal of Fisheries and Aquatic Sciences, 2021, 78 (6), pp.744-751. 10.1139/cjfas-2020-0256 . hal-03322182

\section{HAL Id: hal-03322182 \\ https://hal.inrae.fr/hal-03322182}

Submitted on 18 Aug 2021

HAL is a multi-disciplinary open access archive for the deposit and dissemination of scientific research documents, whether they are published or not. The documents may come from teaching and research institutions in France or abroad, or from public or private research centers.
L'archive ouverte pluridisciplinaire HAL, est destinée au dépôt et à la diffusion de documents scientifiques de niveau recherche, publiés ou non, émanant des établissements d'enseignement et de recherche français ou étrangers, des laboratoires publics ou privés. 
Pagination not final (cite DOI) / Pagination provisoire (citer le DOI)

\title{
Elevated temperature and deposited sediment jointly affect early life history traits in southernmost Arctic char populations
}

\author{
Lisandrina Mari, Martin Daufresne, Jean Guillard, Guillaume Evanno, and Emilien Lasne
}

\begin{abstract}
The combination of global warming and local stressors can have dramatic consequences on freshwater biota. Sediment deposition is an important pressure that can affect benthic species and benthic ontogenetic stages (eggs and larvae) habitat quality. However, knowledge on the effects of sediment in a warming context is lacking. We used a common garden approach to examine the effects of combined exposure to elevated temperature and deposited sediment on early life history traits in offspring of four wild Arctic char (Salvelinus alpinus) populations, originating from geographically isolated lakes at the southern edge of the species range. We report interactive effects of temperature and sediment, with higher temperature exacerbating the negative effects of sediments on the duration of the incubation period and on the body size - yolk expenditure trade-off during development. Our results highlight that reevaluating the impacts of sediment on organisms under the lens of global warming and at the scale of several wild populations is needed to improve our understanding of how vulnerable species can respond to environmental changes.
\end{abstract}

Résumé : La combinaison du réchauffement planétaire et de facteurs de stress locaux peut avoir des conséquences dramatiques sur le biote d'eau douce. Le dépôt de sédiments exerce une importante pression qui peut avoir une incidence sur les espèces benthiques et la qualité de l'habitat de différents stades ontogénétiques (œufs et larves) d'organismes benthiques. Les connaissances sur les effets des sédiments dans un contexte de réchauffement manquent toutefois. Nous utilisons une approche de jardin commun pour examiner les effets de l'exposition combinée à des températures accrues et à des sédiments sur des caractères des premières étapes du cycle biologique de la progéniture de quatre populations sauvages d'ombles chevaliers (Salvelinus alpinus) issus de lacs isolés géographiquement situés à la limite sud de l'aire de répartition de l'espèce. Nous faisons état d'effets interactifs de la température et des sédiments, des températures élevées exacerbant les effets négatifs des sédiments sur la durée de la période d'incubation et sur le compromis entre la taille du corps et l'utilisation du vitellus durant le développement. Nos résultats soulignent le fait qu'il est nécessaire de réévaluer les impacts des sédiments sur les organismes dans une optique du réchauffement planétaire et à l'échelle de plusieurs populations sauvages, afin d'améliorer la compréhension des réactions possibles d'espèces vulnérables aux changements environnementaux. [Traduit par la Rédaction]

\section{Introduction}

Temperature elevations induced by global climate change have been challenging the distribution, physiology, and phenology of species (Parmesan 2006; Bellard et al. 2012; Comte and Olden 2016). Additionally, ecosystems ought to cope with a wide array of local pressures. Because of their interactive effects on the system and its communities (Piggott et al. 2015a, 2015b), multiple stressors have already been acknowledged as one of the causes of the current worldwide decline of freshwater fish populations (I. Côté et al. 2016; Gordon et al. 2018). It is therefore crucial to assess the effects of multiple stressors on biota in a fast-changing climate context, especially on embryo-larval stages that are known to be more sensitive to environmental changes than later life stages (Rombough 1988; Pankhurst and Munday 2011; Lange et al. 2018).

Water temperature and the metabolism, growth, and development rates of fish are firmly linked (Angilletta et al. 2003), thus affecting the life history and fitness of individuals (Zuo et al. 2012; Hemmer-Brepson et al. 2014). Besides, fine sediment (particles of less than $200 \mu \mathrm{m}$ diameter; Argent and Flebbe 1999) accumulation is an important pressure naturally present in freshwater ecosystems (Townsend et al. 2008). However, both anthropogenic activities (agriculture, urbanization) and natural events (flood

Received 10 July 2020. Accepted 11 January 2021.

L. Mari. Institute of Vertebrate Biology, Czech Academy of Sciences, Květná 8, 60365 Brno, Czech Republic; Université Savoie Mont Blanc, Institut national de recherche pour l'agriculture, l'alimentation et l'environnement (INRAE), Centre alpin de recherche sur les reseaux trophiques et écosystèmes limniques (CARRTEL), 74200 Thonon-les-Bains, France.

M. Daufresne. Institut national de recherche pour l'agriculture, l'alimentation et l'environnement (INRAE), Unite de recherche RECOVER, Equipe FRESHCO, Aix-en-Provence, France.

J. Guillard. Université Savoie Mont Blanc, Institut national de recherche pour l'agriculture, l'alimentation et l'environnement (INRAE), Centre alpin de recherche sur les reseaux trophiques et écosystèmes limniques (CARRTEL), 74200 Thonon-les-Bains, France.

G. Evanno. ESE (Ecologie et Santé des Ecosystèmes), Institut national de recherche pour l'agriculture, l'alimentation et l'environnement (INRAE), Agrocampus Ouest, Rennes, France.

E. Lasne. Université Savoie Mont Blanc, Institut national de recherche pour l'agriculture, l'alimentation et l'environnement (INRAE), Centre alpin de recherche sur les reseaux trophiques et écosystèmes limniques (CARRTEL), 74200 Thonon-les-Bains, France; ESE (Ecologie et Santé des Ecosystèmes), Institut national de recherche pour l'agriculture, l'alimentation et l'environnement (INRAE), Agrocampus Ouest, Rennes, France.

Corresponding author: Lisandrina Mari (email: lisandrina.mari@orange.fr).

Copyright remains with the author(s) or their institution(s). Permission for reuse (free in most cases) can be obtained from copyright.com. 
Pagination not final (cite DOI) / Pagination provisoire (citer le DOI)

Can. J. Fish. Aquat. Sci. Vol. 00, 0000

frequency) can boost sediment input in lakes and rivers (Reid et al. 2018). Once deposited, fine sediment affects habitat structure, food availability, and important ecological processes that can in turn alter the overall ecosystem functionality (e.g., organic matter processing; Piggott et al. 2015b) or trophic relationships (Louhi et al. 2017). Owing to its properties that limit oxygen availability, deposited sediment can exert adverse effects on the embryo survival, development, timing of hatching, and growth of many fish species (see Kemp et al. 2011; Chapman et al. 2014), particularly in salmonids that are highly sensitive to breeding habitat degradation (Greig et al. 2007; Jensen et al. 2009; Louhi et al. 2011; Suttle et al. 2004).

Among at-risk species is the Arctic char (Salvelinus alpinus), a cold-water salmonid of cultural and economic importance throughout Northern America and Europe (Klemetsen et al. 2003; Winfield et al. 2018). Distributed across the Northern Hemisphere up to $80^{\circ} \mathrm{N}$ (Klemetsen 2013), the Arctic char is the northernmost freshwater fish species on the planet and has a limited thermal tolerance range compared with other salmonids (Sæther et al. 2016; Baroudy and Elliott 1994b; Elliott and Elliott 2010). Optimal egg incubation occurs at $4-7{ }^{\circ} \mathrm{C}$ (see Sæther et al. 2016; Janhunen et al. 2010), and egg mortality increases dramatically when temperature reaches $8^{\circ} \mathrm{C}$ (Jungwirth and Winkler 1984). In Europe, Arctic char populations of the alpine and peri-alpine region are landlocked and located at the southernmost limit of distribution of the species, where embryo-larval life stages already experience temperatures close to their known upper thermal limit of $8^{\circ} \mathrm{C}$ (Elliott and Elliott 2010). While adults can migrate in the water column to track more suitable conditions, newly hatched individuals remain within the substratum, exhibiting very limited swimming behavior until they reach the first exogenous feeding stage that follows yolk sac absorption (Wallace and Aasjord 1984; Teletchea and Fontaine 2010). Compared with the pelagic larvae of other freshwater fish species, demersal salmonid embryos remain exposed to sediment for extended periods of time, and might be particularly at risk to its accumulation until hatchlings emerge from the substratum (Sternecker et al. 2013).

Since temperature affects oxygen demand and fine sediment reduces oxygen availability in the environment, it is reasonable to hypothesize these two stressors will interact when experienced in combination, as they both affect energy metabolism in a complementary manner (McBryan et al. 2013; Del Rio et al. 2019) and will likely affect primarily cold-water demersal and benthic species in their embryo-larval stages. In a recent study, Mari et al. (2016) showed that temperature influences negatively fine sediment tolerance of embryos of an Arctic char captive brood stock. Much is known about early development and growth of Arctic char in hatchery settings (Jeuthe et al. 2015; Sæther et al. 2016), but few studies have examined the effects of environmental stressors on early life history traits in natural populations (e.g., Swift 1965; Jungwirth and Winkler 1984; Humpesch 1985). Here, we investigate the combined effects of increased temperature and deposited fine sediment on embryonic life history traits of four wild Arctic char populations located at the southern edge of the species distribution. We conducted a common garden experiment, rearing embryos at either an optimum developmental temperature or at a stressful regime close to their upper thermal limit, and in absence or presence of deposited sediment. As we hypothesized that combined exposure to the stressors would affect early life traits more negatively than when experienced separately, our results provide insights into the sensitivity of early life stages of Arctic char to unfavorable environmental conditions and into the variation in response capacity among wild char populations.

\section{Materials and methods}

\section{Ethics statement}

This experiment was designed in accordance with the European Directive 2010/63/EU on the protection of animals used for scientific purposes. As this study focused on fish embryos and larvae that rely on endogenous feeding only, no special ethics permission was required. Permission for fish captures on the field was granted by local authorities.

\section{Study populations}

We collected spawning individuals in December 2016 and January 2017 from four geographically isolated lakes located around the southern limit of the species distribution range in Europe (Fig. 1A): Lake Geneva and Lake Constance (Switzerland-Germany-Austria), where Arctic char is native, and Lake Pavin (France) and Lake SainteCroix, where the species was respectively introduced in 1859 and 1992 from the Lake Geneva population (Machino 1991). In Lake Geneva, allochthonous introductions have been documented in the 1970s, but the population recovered its initial genetic diversity almost entirely today, with no traces of the initial admixture observed (Savary et al. 2017). The Geneva, Constance, and Pavin populations are currently managed through supportive breeding practices, with eggs obtained from local spawners, while the Sainte-Croix population is not managed. These four populations inhabit contrasted thermal habitats, particularly during the egg incubation period, during which average temperatures at spawning ground depths range from $3{ }^{\circ} \mathrm{C}$ (Pavin) to $9^{\circ} \mathrm{C}$ (Sainte-Croix; Fig. 1B).

\section{Spawner capture and embryo rearing conditions}

Spawning adults were caught with gillnets between December 2016 and January 2017 on one spawning ground per lake. Males and females (see online Supplementary Table S1 $1^{1}$ ) were crossed to produce 25 independent families in total. Because of limited spawner availability, the number of families produced varied among populations (Pavin: eight families, Constance: five families (three full-sib and two half-sib families), Geneva: six families, Sainte-Croix: six families). All ova were fertilized in the field at water temperatures between 3 and $5^{\circ} \mathrm{C}$ and brought back to the Institut national de recherche pour l'agriculture, l'alimentation et l'environnement (INRAE) facilities in Thonon-les-Bains, where they were individually distributed into 24 -well cell culture microplates (Nunc MicroWell), a now common setup to rear salmonid eggs experimentally and monitor embryonic development at the individual level (Côte et al. 2012; Wilkins et al. 2015).

We set up two sediment treatments (absence - "control" and presence - "sediment exposed"). In a previous study (Mari et al. 2016), we observed significant effects on survival at a minimal sediment load of $0.015 \mathrm{~g} \cdot \mathrm{cm}^{-2}$ along a gradient of sediment exposure. We selected this load for the exposed treatment in the current study as it represents a low but realistic sedimentation rate (Loizeau et al. 2012) that occurs over the Arctic char egg incubation period in Lake Geneva. We used the same sediment collecting method that is described in Mari et al. (2016). Sediment was collected by pumping water at $51 \mathrm{~m}$ deep in Lake Geneva, then mesh-sieved to retain the $<200 \mu \mathrm{m}$ diameter grain-size fraction, known to be the most harmful to fish early life stages (Kjelland et al. 2015). Sediment was oven-dried $\left(60^{\circ} \mathrm{C}\right.$ for $\left.72 \mathrm{~h}\right)$ prior to being resuspended in mineral water (Volvic; Mari et al. 2016) to obtain a dilution corresponding to our chosen sediment load. After distributing one egg per microplate well, $2 \mathrm{~mL}$ of either clear water or resuspended sediment solution was added to each well of the corresponding microplates. We left sediment to deposit at the bottom of the wells, similarly to the sedimentation process

${ }^{1}$ Supplementary data are available with the article at https://doi.org/10.1139/cjfas-2020-0256. 
Fig. 1. (A) Map of the four source lakes from which spawning individuals were caught. The base map image was created with the maps and ggplot2 packages in $\mathrm{R}$ and was graphically optimized in PowerPoint. (B) Daily average temperature from November to June in the four source lakes. Lakes Pavin and Geneva temperatures were recorded from December 2015 to May 2016 on Arctic char spawning grounds at 14 and $40 \mathrm{~m}$ depth, respectively, using HOBO loggers with one recording every $10 \mathrm{~min}$. Sainte-Croix temperatures were recorded at the lake maximum depth $(60.5 \mathrm{~m})$ from November 2015 to June 2016. Lake Constance temperatures were obtained from already available data at depths corresponding to spawning grounds depths (40 m; Limnological Institute of the University of Konstanz). Shaded area in panel B indicates egg incubation period. [Colour online.]
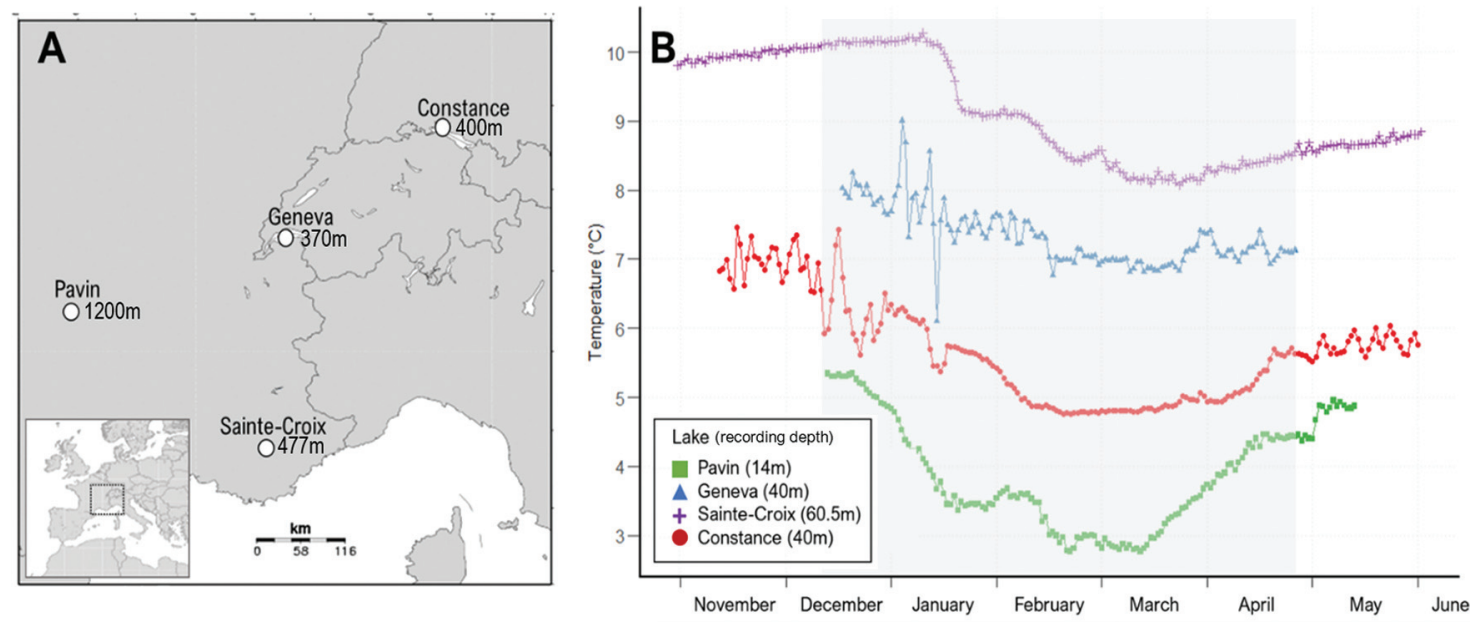

observed in the substratum of spawning areas. Then, plates were split into two batches and incubated in separate climate chambers. In each chamber, plates were randomly distributed on a rack. We set up a cold temperature treatment of $5 \pm 0.090^{\circ} \mathrm{C}$, optimal for development, and a warm treatment of $8.5 \pm 0.038^{\circ} \mathrm{C}$ that is supposedly stressful, but experienced by the species on spawning grounds of Lakes Geneva and Sainte-Croix (Mari et al. 2016). Temperature was recorded from fertilization to hatching using HOBO loggers (HOBO Onset, model No. UX100-001).

We used duplicates of 12 eggs per family per population in plates containing no sediments and triplicates of 12 eggs in sediment plates, as we were expecting higher mortality in sedimentexposed individuals (total of 2640 eggs, two families per plate). For the Sainte-Croix population, sediment effect was tested on three families out of six, because three females produced clutches of fewer than 100 eggs.

\section{Early life trait measurements}

Each plate was photographed at the beginning of the experiment (Nikon D5300 and Nikon DX 18-105 mm lens). Individual egg size was measured to the nearest $0.01 \mathrm{~mm}$ as the mean diameter (average of two perpendicular diameters) of the egg. Plates were initially left to incubate in the dark so as to not disturb the first stages of development during the first week of incubation and were then monitored daily (every morning) during hatching period. Each newly hatched fish was anaesthetized with $0.35 \mathrm{~mL}$ eugenol- $\mathrm{L}^{-1}$ (i.e., clove oil diluted 1:10 into 95\% ethanol) and photographed individually using the same setup as described above. Body size was measured as the length from the snout to the end of tail (total length in mm, TL), and yolk sac volume (YSV) was calculated using the following formula: YSV $=\pi / 6 \times L \times H^{2}$ (with $L=$ major axis and $H=$ minor axis, in $\mathrm{mm}$; see Kamler 2005). Individual egg size, length, and yolk sac axes at hatching were measured using IMAGEJ (http://rsbweb.nih.gov/ij/download.html). Because sediment-exposed eggs were fully covered by a sediment layer, we could not measure fertilization success and early-life mortality at eyed stage. Thus, survival was estimated as the number of hatched embryos divided by the number of eggs per family. While including unfertilized eggs might bias survivorship rates downwards, it allows accounting for any mortality that occurred before the eyed stage. However, fertilization success can vary among and within populations. Thus, to allow population comparisons, we standardized survival estimates relative to the trait value in the most optimal environment for egg development, that is, the control (cold, no sediment) treatment as standardized survival = $x_{\text {treatment }} / \mu_{\text {control, }}$, with $x$ being mean survival of a given family; treatment being one of the four treatments (cold, cold exposed, warm, warm exposed); and $\mu_{\text {control }}$ being mean survival of a given family in the control treatment. Incubation period was calculated from the number of days from fertilization to hatching as a development rate in accumulated degree days (ADDs): $\mathrm{ADD}=$ mean daily temperature $\times$ number of days between fertilization and hatching date. ADD represents the heat accumulated by developing embryos until hatching (Crisp 1981) and thus constitute a more biologically relevant metric for incubation duration than days.

\section{Statistical analyses}

All analyses were performed using $\mathrm{R}$ version 3.6.2 ( $\mathrm{R}$ Core Team 2019), applying a critical significance threshold of 0.05 . We analyzed the relationship between the relative changes in life history trait values and treatments using linear mixed models (LMM and GLMM) with the lme4 package (Bates et al. 2015). We ran one mixed model per trait to test for global effects of treatments, as well as differences among populations. We used a Gaussian error distribution following log transformation to improve normality and homoscedasticity in incubation duration, body size, and YSV models and a binomial distribution for survival model. Temperature and sediment treatments and their interaction and population origin were specified as fixed effects, whereas family identity was set as random effect. Plate identity was set as random effect in all models except survival, because this trait was calculated at the family level instead of individually. Incubation duration was included as a fixed covariate in all body size and YSV models. Owing to the importance of maternal investment in egg size in salmonids (Leblanc et al. 2014; Perry et al. 2005; Polymeropoulos et al. 2016), individual egg size was included as a fixed covariate in all models. All mixed models were fitted under maximum-likelihood 
Table 1. Linear mixed model testing for the overall effects of temperature, sediment exposure, population, and one- and two-way interactions on relative changes in survival, incubation duration, size, and yolk sac volume (YSV) at hatching.

\begin{tabular}{|c|c|c|c|c|c|c|c|c|c|}
\hline \multirow[b]{2}{*}{ Fixed effects } & \multirow[b]{2}{*}{ df } & \multicolumn{2}{|c|}{ Survival $(n=2640)$} & \multicolumn{2}{|c|}{ Incubation $(n=1540)$} & \multicolumn{2}{|c|}{ Length $(n=1540)$} & \multicolumn{2}{|c|}{ YSV $(n=1540)$} \\
\hline & & $\chi^{2}$ & $p$ & $\chi^{2}$ & $p$ & $\chi^{2}$ & $p$ & $\chi^{2}$ & $p$ \\
\hline Temperature & 1 & 32.54 & $<0.001$ & 320.03 & $<0.001$ & 181.01 & $<0.001$ & 19.13 & $<0.001$ \\
\hline Sediment load & 1 & 2.22 & 0.136 & 0.20 & 0.655 & 119.19 & $<0.001$ & 0.74 & 0.390 \\
\hline Population & 3 & 16.95 & $<0.001$ & 29.79 & $<0.001$ & 21.23 & $<0.001$ & 14.02 & 0.003 \\
\hline Temperature $\times$ population & 3 & 3.93 & 0.270 & 20.53 & $<0.001$ & 12.84 & 0.005 & 32.19 & $<0.001$ \\
\hline Sediment load $\times$ population & 3 & 5.30 & 0.506 & 29.20 & $<0.001$ & 5.99 & 0.112 & 10.86 & 0.030 \\
\hline ADD & 1 & - & - & - & - & 72.29 & $<0.001$ & 0.35 & 0.555 \\
\hline
\end{tabular}

Note: Bold values indicate $p<0.05$ (likelihood ratio tests). ADD, accumulated degree days.

Fig. 2. Effects of the four treatments on (A) standardized survival rate $(n=2640)$, (B) length of incubation period $(n=1540)$, (C) length at hatching $(n=1540)$, and (D) yolk sac volume (YSV) at hatching $(n=1540)$ for the four study populations. For each treatment, from left to right: blue: Pavin, green: Constance, yellow: Geneva, orange: Sainte-Croix. Values are expressed as mean \pm SE. Letters indicate significant post hoc differences between populations within each treatment and between treatments within each population $(p<0.05$, BenjaminiHochberg correction). Note that survival is represented here as a rate standardized to the survival rate observed in cold control for clarity, but testing was performed on raw survival data, hence the differences observed among populations in the control treatment. All other traits are represented as raw data. [Colour online.]
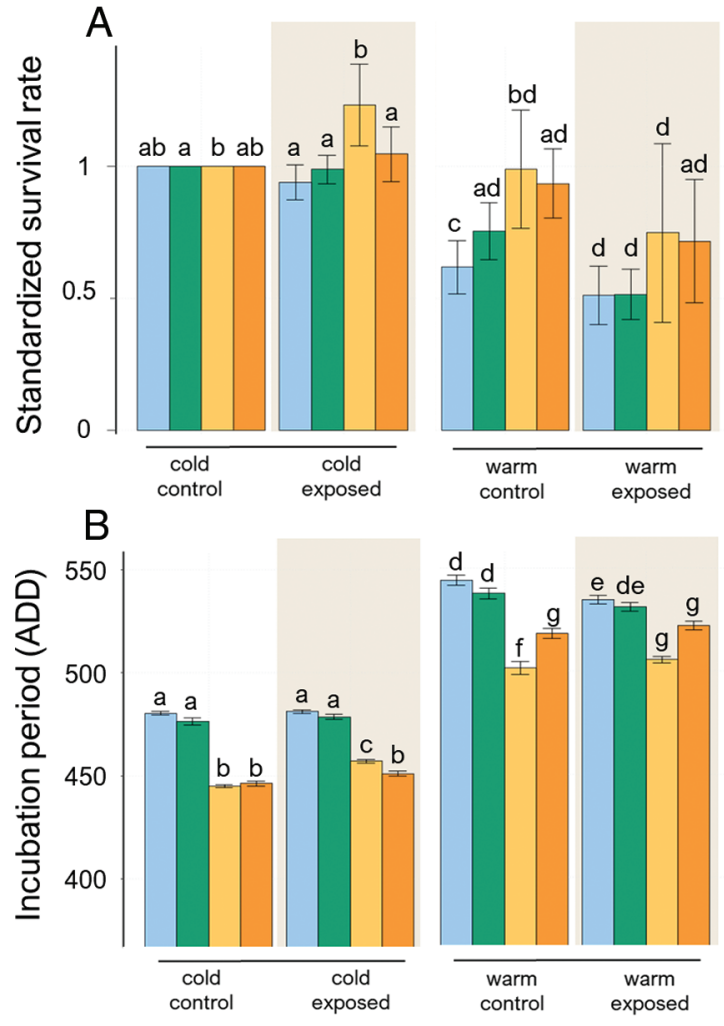

estimation. The significance of independent variable was tested by comparing models including or not including the explanatory variable(s) of interest with likelihood ratio tests, and all residuals for selected models were inspected visually ( $Q-Q$ plots) to ensure they did not deviate from assumptions of normality and homoscedasticity. We then performed post hoc multiple pairwise population comparisons in each treatment and between treatments in each population. Pairwise differences were estimated using the emmeans package in $\mathrm{R}$ (Lenth et al. 2018), applying a BenjaminiHochberg correction to account for false discovery rate (Yekutieli and Benjamini 2001).
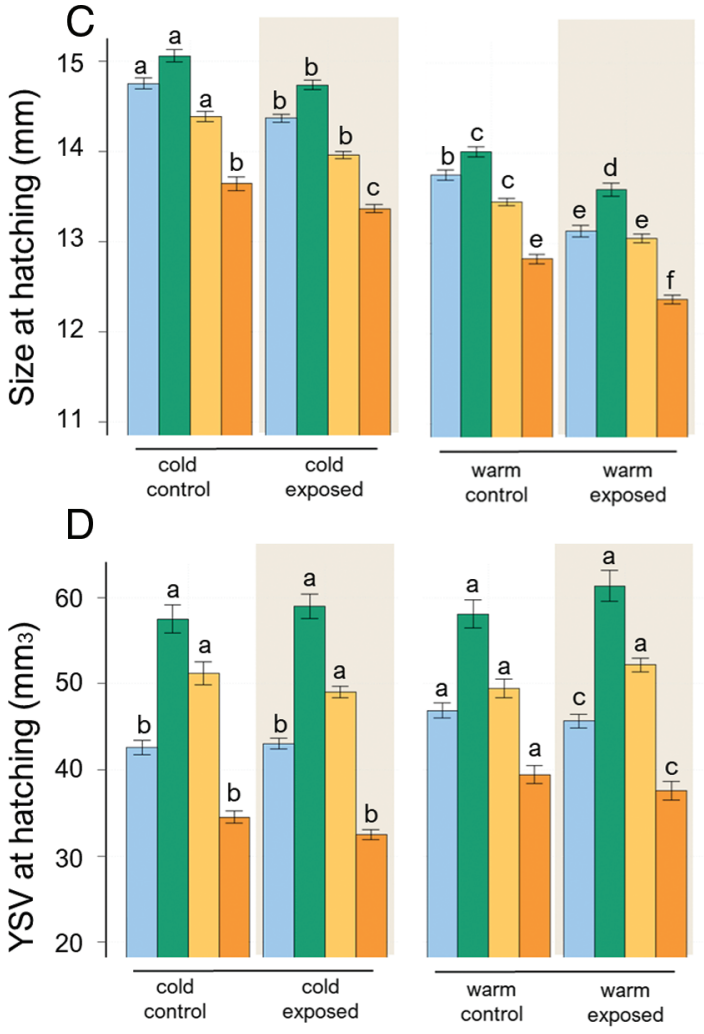

\section{Results}

Effects of temperature and sediment on survival

Overall, temperature had a significant negative effect on survival (Table 1). Post hoc testing revealed significantly lower survival in the Constance and Pavin populations in the warm exposed treatment both with and without sediment (Fig. 2), appearing to be the most affected by warm temperatures during development. Survival declined by $25 \%$ and $40 \%$, respectively, when exposed to warmer temperature alone and by $50 \%$ for embryos of both origins when exposed to temperature and sediment in combination. 
Pagination not final (cite DOI) / Pagination provisoire (citer le DOI)

\section{Effects of temperature and sediment on incubation period}

Incubation period, measured in ADDs, was significantly longer in the warm treatment for all populations (Table 1). There was no effect of sediment exposure on incubation period overall, but the temperature $\times$ sediment interaction was significant. The model showed differences among populations in their responses to temperature and sediment exposure (significant interactions with population; Table 1). The sediment effect was found to significantly increase incubation period in the Geneva population both under cold and warm conditions (significant post hoc testing; Fig. 2). Conversely, we observed a significant decrease in incubation period due to sediment in the warm treatment for the Constance and Pavin populations. This trait was unaffected by sediment in Sainte-Croix individuals. Initial egg size did not have an effect on the duration of the incubation period.

\section{Effects of temperature and sediment on body size and YSV}

The size of embryos was influenced by their origin and the temperature experienced throughout development (Table 1). Sedimentexposed individuals were smaller than individuals in the control treatment. Size decreased even more substantially under warm exposed conditions; individuals suffered a $10 \%$ reduction in size when they experienced both stressors in combination (compared with control; Fig. 2). Along with a significant temperature $\times$ sediment interaction, we detected a significant temperature $\times$ population interaction. Body size, length of incubation period, and initial egg size were positively linked. Temperature and sediment together did not affect YSV (Table 1). YSV varied among populations overall and within treatments. Pavin and Sainte-Croix individuals had bigger yolk sacs in the warmer treatment. Sediment exposure had a negative effect on the yolk volume of Sainte-Croix individuals only, observable both at cold and warm conditions (Fig. 2).

\section{Discussion}

This study focused on the influence of two major pressures in fresh waters, deposited sediment and increased temperature, on early life stages of southernmost Arctic char populations. It illustrates that $(i)$ combined elevated temperatures and sediment-rich waters can affect fitness-related traits interactively and (ii) wild alpine $S$. alpinus populations have different susceptibilities to these pressures. Because temperature affects biochemical rates of reactions, it is a crucial parameter for early fish development. Our results reflect trait responses that are typically associated with thermal stress in salmonids, such as reduced size and earlier hatching under warmer conditions (Ojanguren and Braña 2004; J. Côte et al. 2016).

Individuals from the Constance and Geneva populations reared in the warm treatment were smaller but had a YSV similar to that of cold treatment conspecifics. This indicates that part of the yolk reserves were not allocated to growth, likely revealing a physiological stress response (Valdimarsson et al. 2002). When yolk conversion efficiency is lower, growth rates are reduced (Heming 1982; Ojanguren and Braña 2004; Kamler 2008), which could explain the observed smaller size at hatching and changes in yolk reserve expenditure. Sediment effects were less pervasive than temperature effects, and we did not detect any changes in survival. In literature, sediment has been linked with a decrease in embryo survival of other salmonids, such as Atlantic salmon (Salmo salar) (Levasseur et al. 2006) and brown trout (Salmo trutta) (Sear et al. 2016). It is important to note that the amount of sediment to which embryos were exposed in this experiment was rather low compared with known sedimentation rates (e.g., up to $1 \mathrm{~g} \cdot \mathrm{cm}^{-2} \cdot$ year $^{-1}$ in Lake Geneva; Loizeau et al. 2012). We deliberately used a low but realistic sediment level because detailed information on the local sedimentation conditions in the other source lakes was not available. However, field observations point at the presence of excess organic matter at the bottom of Lake
Pavin, clogging potential char breeding habitat (Desmolles 2016). Sediment was found to affect size of individuals at hatching but not yolk reserves. Incubation period did not vary significantly with sediment exposure, except in the Geneva population for which hatching was slightly delayed. This pattern is nonetheless consistent with our previous findings on char embryos exposed at a similarly low sediment level (Mari et al. 2016) and with other studies that showed that sediment exposure can negatively affect fish larval development, growth (Greig et al. 2005; Sear et al. 2014; Kjelland et al. 2015), and even metabolic performance (Hess et al. 2015, 2017).

In accordance with our initial hypothesis that sediment would exert more harmful effects on life history traits under warm conditions, we detected sublethal effects of sediment in the warm treatment. The population of origin was an important factor in the response of char embryos to temperature and fine sediment, as population appeared to be a significant variable in all models. Although the magnitude of the response to the two stressors experienced in combination was rather weak, the four populations exhibited distinct response patterns. In the populations in which hatched individuals exhibited bigger yolks (Pavin and Sainte-Croix), hatched embryos were much smaller. Temperature alone affected survival strongly, but temperature and sediment did not show significantly interactive effects on survival. When higher temperature and sediment were experienced simultaneously, incubation was significantly shorter than in the control treatment in days, but not in ADD. Our results further showed that ADD requirements until hatching were population-specific and varied with exposure to temperature, sediment, or both stressors. Hatching might occur earlier to compensate the high metabolic costs of an unfavorable environment (Wedekind and Müller 2005; Storm and Angilletta 2007). As example, Constance individuals hatched at fewer ADDs when exposed to both stressors, compared with their conspecifics exposed to warm temperature only, meaning development was accelerated. Conversely, Geneva individuals hatched at a later age in ADDs. Since the hatching process itself is energetically costly (Kamler 2008), hatching can also be delayed because meeting the energy demand necessary for hatching under warm conditions with limited oxygen availability can be more difficult (McBryan et al. 2013). This will be likely linked to the individuals capacity to partition yolk among different physiological functions (respiratory functions, development, organogenesis, growth) that will lead to the establishment of tradeoffs during early life (Stearns 1992; Carlson et al. 2004; Kavanagh et al. 2010). This further suggests other physiological or behavioral alterations that would be relevant to investigate, particularly in regard to how early life exposure to temperature and fine sediment may carry effects into later life stages. However, although oxygen limitation can have severe consequences on embryonic traits of salmonids (Côte et al. 2012; Del Rio et al. 2019; Lavery and Cunjak 2019) and induce immediate and long-lasting alterations in the cardiovascular system of adults (Miller et al. 2011; Johnston et al. 2013; Anttila et al. 2015), evidence regarding consequences of early life hypoxia on adult performance is mixed (Wood et al. 2017), and further studies are needed to characterize the long-term effects of developmental environment on salmonid physiology.

Interactive effects of temperature and sediment were less pronounced than expected based on what was observed previously in a captive char brood stock (Mari et al. 2016), where the two stressors combined had induced a $25 \%$ decrease in survival and a much shorter incubation period. Captive brood stocks are generally held in artificial conditions (high water quality, nonstressful temperatures), in which adaptation can occur rapidly (Christie et al. 2012). In the present study, our results indicate that wild populations seem to be better adapted than captive fish to exposure to a low but realistic sediment load. This could potentially raise questions on the consequences of supportive breeding practices on the population's capacity to respond to environmental 
Pagination not final (cite DOI) / Pagination provisoire (citer le DOI)

Can. J. Fish. Aquat. Sci. Vol. 00, 0000

stressors. Considering three out of the four populations studied are managed, future research in this direction would be extremely relevant to help management strategies make informed decisions to maintain wild populations. Salmonid early life is tightly linked to maternal provisioning (Perry et al. 2004; Leblanc et al. 2014), which we took into account as individual egg size in this study, although we did not measure egg quality (e.g., yolk composition). Average egg size varied among populations (Supplementary Fig. S2 ${ }^{1}$ ), which could be due to local conditions, genetic divergence, and (or) differences in individual size, as larger females tend to produce larger eggs (Leblanc et al. 2014). This variation is very likely to have contributed to differences observed among populations in length of incubation period, size at hatching, and YSV in the control treatment. Since yolk reserves constitute the only nutritional source available to embryos, egg size variation could have promoted response variability among and within populations, likely through maternal effects. Maternal investment in egg size is known to influence heavily size and energetic reserves in offspring (as seen in fish (Einum et al. 2002; Régnier et al. 2012) or amphibians (Räsänen et al. 2005)). The crossing design used in the present study was not drawn to disentangle genetic (sire and dam combination) from maternal effects, which were both accounted for under a single random effect (termed family identity; Supplementary Table $S 3^{1}$ ). However, in such a common garden experiment with individual egg size as a covariate in statistical analyses, differences among populations reflect to some extent genetic effects. Among- and within-population variation highlights the existing genetic variability that is the basis for responding adaptively to future environmental changes. Furthermore, since the populations of Geneva, Pavin, and Sainte-Croix have the same genetic background and their divergence occurred recently (i.e., over decades), a larger quantitative genetics crossing design might help to investigate whether the different responses we observed could have emerged from local adaptations to local thermal and sedimentation conditions.

Our results show a limited, but significant, interaction between temperature and fine sediment on early life history traits and highlight the negative effects of increased temperature in offspring of wild salmonid populations, with relevance for the conservation of declining Arctic char populations. The species is known to have a lower thermal tolerance and lower capacity to acclimate to higher temperatures than other salmonids, favoring cold, well-oxygenated water (Baroudy and Elliott 1994a; Elliott and Elliott 2010; Anttila et al. 2015). While environmental conditions in European lakes are changing quickly (Salmaso et al. 2018), adults may be able to seek refugia in deeper waters (Jensen et al. 2017; Jones et al. 2008), and a priority might thus be to maintain good overwintering habitat quality and cold-water refugia. In deep, low-elevation lakes, temperature might exceed Arctic char tolerance threshold levels and induce lethal and sublethal effects on embryos, with implications for later reproductive stages, since elevated temperatures can greatly affect later spawning success and next generation offspring quality (Gillet 1991; Gillet et al. 2011; Jeuthe et al. 2015). In alpine shallow high-elevation lakes, temperature in spawning grounds during egg incubation is several degrees below the stressful condition of $8.5^{\circ} \mathrm{C}$ that was tested in the present study. Although mountain lakes are highly vulnerable to climate change, with faster projected warming and reduction of ice and snow cover (Thompson et al. 2005), temperature increases probably do not constitute a critical short-term threat for Arctic char early life stages yet. However, many pressures other than temperature may be of concern in the current multiple stressor context, including suspended sediment that can exert destructive effects on fish (Shrimpton et al. 2007; Berli et al. 2014; Chapman et al. 2014), pollutants, and abiotic pressures such as predation or interspecific competition with native and invasive species (Caudron et al. 2014; Morrissey-McCaffrey et al. 2019), all of which warrant further attention.

\section{Data availability statement}

The data from this experiment has been uploaded to the Mendeley Data public repository (see Mari et al. 2019).

\section{Acknowledgements}

L'office français de la biodiversité (OFB) (l'office national de l'eau et des milieux aquatiques, ONEMA 2016-2018) provided funding for the experiment. LM was supported by a French Ministry for Research fellowship. The authors thank the APERA, LAZBW Langenargen, and the Fédération de Pêche du Puy de Dôme staff for logistical assistance and contribution of spawning individuals; Laurent Espinat, Jean-Christophe Hustache, and Ayala Loisel for assistance on the field; the Environmental Physics group at the Limnological Institute of the University of Konstanz for providing temperature data for Lake Constance; and Ayala Loisel for providing temperature data for Lake SainteCroix. We thank two anonymous reviewers for their insightful comments on an earlier version of the manuscript. The authors declare they have no conflict of interest.

\section{References}

Angilletta, M.J., Wilson, R.S., Navas, C.A., and James, R.S. 2003. Tradeoffs and the evolution of thermal reaction norms. Trends Ecol. Evol. 18(5): 234-240. doi:10.1016/S0169-5347(03)00087-9.

Anttila, K., Lewis, M., Prokkola, J.M., Kanerva, M., Seppänen, E., Kolari, I., and Nikinmaa, M. 2015. Warm acclimation and oxygen depletion induce species-specific responses in salmonids. J. Exp. Biol. 218(Pt. 10): 1471-1477. doi:10.1242/jeb.119115. PMID:25827840.

Argent, D.G., and Flebbe, P.A. 1999. Fine sediment effects on brook trout eggs in laboratory streams. Fish. Res. 39: 253-262. doi:10.1016/S0165-7836 (98)00188-X.

Baroudy, E., and Elliott, J.M. 1994a. Tolerance of parr of Arctic charr, Salvelinus alpinus, to reduced dissolved oxygen concentrations. J. Fish Biol. 44: 736-738. doi:10.1111/j.1095-8649.1994.tb01250.x.

Baroudy, E., and Elliott, J.M. 1994b. The critical thermal limits for juvenile Arctic charr Salvelinus alpinus. J. Fish Biol. 45: 1041-1053. doi:10.1111/j.10958649.1994.tb01071.x.

Bates, D., Mächler, M., Bolker, B., and Walker, S. 2015. Fitting linear mixedeffects models using lme4. J. Stat. Softw. 67(1): 1-48. doi:10.18637/jss.v067. i01.

Bellard, C., Bertelsmeier, C., Leadley, P., Thuiller, W., and Courchamp, F. 2012. Impacts of climate change on the future of biodiversity. Ecol. Lett. 15(4): 365-377. doi:10.1111/j.1461-0248.2011.01736.x. PMID:22257223.

Berli, B.I., Gilbert, M.J.H., Ralph, A.L., Tierney, K.B., and Burkhardt-Holm, P. 2014. Acute exposure to a common suspended sediment affects the swimming performance and physiology of juvenile salmonids. Comp. Biochem. Physiol. Part A Mol. Integr. Physiol. 176: 1-10. doi:10.1016/j.cbpa.2014.03.013. PMID:24909119.

Carlson, S.M., Hendry, A.P., and Letcher, B.H. 2004. Natural selection acting on body size, growth rate and compensatory growth: an empirical test in a wild trout population. Evol. Ecol. Res. 6(7): 955-973. doi:10.1007/s00415009-0947-6.

Caudron, A., Lasne, E., Gillet, C., Guillard, J., and Champigneulle, A. 2014. Thirty years of reoligotrophication do not contribute to restore selfsustaining fisheries of Arctic charr, Salvelinus alpinus, in Lake Geneva. Fish. Res. 154: 165-171. doi:10.1016/j.fishres.2014.01.023.

Chapman, J.M., Proulx, C.L., Veilleux, M.A.N., Levert, C., Bliss, S., André, M.-È., et al. 2014. Clear as mud: a meta-analysis on the effects of sedimentation on freshwater fish and the effectiveness of sediment-control measures. Water Res. 56: 190-202. doi:10.1016/j.watres.2014.02.047. PMID:24681235.

Christie, M.R., Marine, M.L., French, R.A., and Blouin, M.S. 2012. Genetic adaptation to captivity can occur in a single generation. Proc. Natl. Acad. Sci. 109(1): 238-242. doi:10.1073/pnas.1111073109. PMID:22184236.

Comte, L., and Olden, J.D. 2016. Evolutionary and environmental determinants of freshwater fish thermal tolerance and plasticity. Global Change Biol. 23: 728-736. doi:10.1111/gcb.13427. PMID:27406402.

Côté, I.M., Darling, E.S., and Brown, C.J. 2016. Interactions among ecosystem stressors and their importance in conservation. Proc. R. Soc. B Biol. Sci. 283: 1824. doi:10.1098/rspb.2015.2592.

Côte, J., Roussel, J.-M., Le Cam, S., Bal, G., and Evanno, G. 2012. Population differences in response to hypoxic stress in Atlantic salmon. J. Evol. Biol. 25(12): 2596-2606. doi:10.1111/jeb.12007. PMID:23107024.

Côte, J., Roussel, J.-M., Le Cam, S., Guillaume, F., and Evanno, G. 2016. Adaptive divergence in embryonic thermal plasticity among Atlantic salmon populations. J. Evol. Biol. 29: 1593-1601. doi:10.1111/jeb.12896. PMID:27177256. 
Crisp, D.T. 1981. A desk study of the relationship between temperature and hatching time for the eggs of five species of salmonid fishes. Freshw. Biol. 11(4): 361-368. doi:10.1111/j.1365-2427.1981.tb01267.x.

Del Rio, A.M., Davis, B.E., Fangue, N.A., and Todgham, A.E. 2019. Combined effects of warming and hypoxia on early life stage Chinook salmon physiology and development. Conserv. Physiol. 7: 1-14. doi:10.1093/conphys/ coy078. PMID:30834124.

Desmolles, F. 2016. History of the fish fauna of Lake Pavin: a population heavily influenced by man? Edited by T. Sime-Ngando, P. Boivin, E. Chapron, D. Jezequel, and M. Meybeck. Springer. doi:10.1007/978-3-319-39961-4.

Einum, S., Hendry, A.P., and Fleming, I.A. 2002. Egg-size evolution in aquatic environments: does oxygen availability constrain size? Proc. R. Soc. B Biol. Sci. 269(1507): 2325-2330. doi:10.1098/rspb.2002.2150. PMID:12495499.

Elliott, J.M., and Elliott, J.A. 2010. Temperature requirements of Atlantic salmon Salmo salar, brown trout Salmo trutta and Arctic charr Salvelinus alpinus: Predicting the effects of climate change. J. Fish Biol. 77(8): 17931817. doi:10.1111/j.1095-8649.2010.02762.x. PMID:21078091.

Gillet, C. 1991. Egg production in an Arctic charr (Salvelinus alpinus L.) brood stock: effects of temperature on the timing of spawning and the quality of eggs. Aquat. Living Resour. 4: 109-116. doi:10.1051/alr:1991010.

Gillet, C., Breton, B., Mikolajczyk, T., Bodinier, P., and Fostier, A. 2011. Disruption of the secretion and action of 17,20ß-dihydroxy-4-pregnen-3-one in response to a rise in temperature in the Arctic charr, Salvelinus alpinus. Consequences on oocyte maturation and ovulation. Gen. Comp. Endocrinol. 172(3): 392-399. doi:10.1016/j.ygcen.2011.04.002. PMID:21501615.

Gordon, T.A.C., Harding, H.R., Clever, F.K., Davidson, I.K., Davison, W., Montgomery, D.W., et al. 2018. Fishes in a changing world: learning from the past to promote sustainability of fish populations. J. Fish Biol. 92: 804-827. doi:10.1111/jfb.13546. PMID:29537086.

Greig, S.M., Sear, D.A., and Carling, P.A. 2005. The impact of fine sediment accumulation on the survival of incubating salmon progeny: implications for sediment management. Sci. Total Environ. 344(1-3): 241-258. doi:10.1016/j.scitotenv.2005.02.010. PMID:15893806.

Greig, S., Sear, D., and Carling, P. 2007. A field-based assessment of oxygen supply to incubating Atlantic salmon (Salmo salar) embryos. Hydrol. Processes Int. J. 21: 3087-3100. doi:10.1002/hyp.

Heming, T.A. 1982. Effects of temperature on utilization of yolk by chinook salmon (Oncorhynchus tshawytscha) eggs and alevins. Can. J. Fish. Aquat. Sci. 39(1): 184-190. doi:10.1139/f82-021.

Hemmer-Brepson, C., Replumaz, L., Romestaing, C., Voituron, Y., and Daufresne, M. 2014. Non-stressful temperature effect on oxidative balance and life history traits in adult fish (Oryzias latipes). J. Exp. Biol. 217(2): 274-282. doi:10.1242/jeb.096172. PMID:24115055.

Hess, S., Wenger, A.S., Ainsworth, T.D., and Rummer, J.L. 2015. Exposure of clownfish larvae to suspended sediment levels found on the Great Barrier Reef: impacts on gill structure and microbiome. Nat. Publ. Gr. 5: 10561. doi:10.1038/srep10561. PMID:26094624.

Hess, S., Prescott, L.J., Hoey, A.S., Mcmahon, S.A., Wenger, A.S., Rummer, J.L., and Hess, S. 2017. Species-specific impacts of suspended sediments on gill structure and function in coral reef fishes. Proc. R Soc. B Biol. Sci. 284: 20171279. .doi:10.1098/rspb.2017.1279. PMID:29093217.

Humpesch, U.H. 1985. Inter specific and intra specific variation in hatching success and embryonic development of 5 species of salmonids and Thymallus thymallus. Arch. Fuer Hydrobiol. 104(1): 129-144. Available from https:// eurekamag.com/research/005/719/005719652.php.

Janhunen, M., Piironen, J., and Peuhkuri, N. 2010. Parental effects on embryonic viability and growth in Arctic charr Salvelinus alpinus at two incubation temperatures. J. Fish Biol. 76(10): 2558-2570. doi:10.1111/j.1095-8649. 2010.02648.x. PMID:20557608.

Jensen, D.W., Steel, E.A., Fullerton, A.H., and Pess, G.R. 2009. Impact of fine sediment on egg-to-fry survival of pacific salmon: a meta-analysis of published studies. Rev. Fish. Sci. 17(3): 348-359. doi:10.1080/10641260902716954.

Jensen, H., Kiljunen, M., Knudsen, R., and Amundsen, P.A. 2017. Resource partitioning in food, space and time between Arctic charr (Salvelinus alpinus), brown trout (Salmo trutta) and European whitefish (Coregonus lavaretus) at the southern edge of their continuous coexistence. PLoS ONE, 12(1): 1-18. doi:10.1371/journal.pone.0170582. PMID:28122061.

Jeuthe, H., Brännäs, E., and Nilsson, J. 2015. Thermal stress in Arctic charr Salvelinus alpinus broodstock: a 28 year case study. J. Fish Biol. 86(3): 11391152. doi:10.1111/jfb.12634. PMID:25683742.

Johnston, E.F., Alderman, S.L., and Gillis, T.E. 2013. Chronic hypoxia exposure of trout embryos alters swimming performance and cardiac gene expression in larvae. Physiol. Biochem. Zool. 86(5): 567-575. doi:10.1086/ 672012. PMID:23995487.

Jones, I.D., Winfield, I.J., and Carse, F. 2008. Assessment of long-term changes in habitat availability for Arctic charr (Salvelinus alpinus) in a temperate lake using oxygen profiles and hydroacoustic surveys. Freshw. Biol. 53(2): 393-402. doi:10.1111/j.1365-2427.2007.01902.x.

Jungwirth, M., and Winkler, H. 1984. The temperature dependence of embryonic development of grayling. Aquaculture, 38(4): 315-327. doi:10.1016/ 0044-8486(84)90336-3.

Kamler, E. 2005. Parent-egg-progeny relationships in teleost fishes: an energetics perspective. Rev. Fish Biol. Fish. 15(4): 399-421. doi:10.1007/s11160006-0002-y.
Kamler, E. 2008. Resource allocation in yolk-feeding fish. Rev. Fish Biol. Fish. 18(2): 143-200. doi:10.1007/s11160-007-9070-x.

Kavanagh, K.D., Haugen, T.O., Gregersen, F., Jernvall, J., and Vøllestad, L.A. 2010. Contemporary temperature-driven divergence in a Nordic freshwater fish under conditions commonly thought to hinder adaptation. BMC Evol. Biol. 10(1): 350. doi:10.1186/1471-2148-10-350. PMID:21070638.

Kemp, P., Sear, D., Collins, A., Naden, P., and Jones, I. 2011. The impacts of fine sediment on riverine fish. Hydrol. Process. 25(11): 1800-1821. doi:10.1002/ hyp.7940.

Kjelland, M.E., Woodley, C.M., Swannack, T.M., and Smith, D.L. 2015. A review of the potential effects of suspended sediment on fishes: potential dredging-related physiological, behavioral, and transgenerational implications. Environ. Syst. Decis. 35(3): 334-350. doi:10.1007/s10669-015-9557-2.

Klemetsen, A. 2013. The most variable vertebrate on earth. J. Ichthyol. 53(10): 781-791. doi:10.1134/S0032945213100044.

Klemetsen, A., Amundsen, P.-A., Dempson, J.B., Jonsson, B., Jonsson, N., O'Connell, M.F., and Mortensen, E. 2003. Atlantic salmon Salmo salar L., brown trout Salmo trutta L. and Arctic charr Salvelinus alpinus (L.): a review of aspects of their life histories. Ecol. Freshw. Fish. 12(1): 1-59. doi:10.1034/ j.1600-0633.2003.00010.x.

Lange, K., Bruder, A., Matthaei, C.D., Brodersen, J., and Paterson, R.A. 2018. Multiple-stressor effects on freshwater fish: importance of taxonomy and life stage. Fish Fish. 19: 974-983. doi:10.1111/faf.12305.

Lavery, J.M., and Cunjak, R.A. 2019. The influence of abiotic incubation conditions on the winter mortality of wild salmonid embryos. Freshw. Biol. 64(6): 1098-1113. doi:10.1111/fwb.13280.

Leblanc, C.A.-L., Kristjánsson, B.K., and Skúlason, S. 2014. The importance of egg size and egg energy density for early size patterns and performance of Arctic charr Salvelinus alpinus. Aquac. Res. 47: 1100-1111. doi:10.1111/ are.12566.

Lenth, R., Singmann, H., Love, J., Buerkner, P., and Herve, M. 2018. Emmeans: Estimated marginal means, aka least-squares means. $\mathrm{R}$ package version, 1(1), p. 3.

Levasseur, M., Bergeron, N.E., Lapointe, M.F., and Bérubé, F. 2006. Effects of silt and very fine sand dynamics in Atlantic salmon (Salmo salar) redds on embryo hatching success. Can. J. Fish. Aquat. Sci. 63(7): 1450-1459. doi:10.1139/ f06-050.

Loizeau, J.-L., Girardclos, S., and Dominik, J. 2012. Taux d'accumulation de sédiments récents et bilan de la matière particulaire dans le Léman (Suisse-France). Arch. Des. Sci. 65(January): 81-92.

Louhi, P., Ovaska, M., Mäki-Petäys, A., Erkinaro, J., Muotka, T., and Rosenfeld, J. 2011. Does fine sediment constrain salmonid alevin development and survival? Can. J. Fish. Aquat. Sci. 68(10): 1819-1826. doi:10.1139/f2011-106.

Louhi, P., Richardson, J.S., and Muotka, T. 2017. Sediment addition reduces the importance of predation on ecosystem functions in experimental stream channels. Can. J. Fish. Aquat. Sci. 74(1): 32-40. doi:10.1139/cjfas2015-0530.

Machino, Y. 1991. Répartition géographique de l'omble chevalier (poisson, Salmonidae, Salvelinus alpinus) en France. Diplôme Supérieur de Recherches.

Mari, L., Garaud, L., Evanno, G., and Lasne, E. 2016. Higher temperature exacerbates the impact of sediments on embryo performances in a salmonid. Biol. Lett. 12(12): 20160745. doi:10.1098/rsbl.2016.0745. PMID:28003520.

Mari, L., Daufresne, M., Guillard, J., Evanno, G., and Lasne, E. 2019. Data from: Combined exposure to elevated temperature and deposited sediment reveals contrasted early life responses among southernmost Arctic charr populations. Mendeley Data, v1. Available from http://dx.doi.org/ 10.17632/wbhs5hkx49.1.

McBryan, T.L., Anttila, K., Healy, T.M., and Schulte, P.M. 2013. Responses to temperature and hypoxia as interacting stressors in fish: implications for adaptation to environmental change. Integr. Comp. Biol. 53(4): 648-659. doi:10.1093/icb/ict066. PMID:23784697.

Miller, S.C., Gillis, T.E., and Wright, P.A. 2011. The ontogeny of regulatory control of the rainbow trout (Oncorhynchus mykiss) heart and how this is influenced by chronic hypoxia exposure. J. Exp. Biol. 214(12): 2065-2072. doi:10.1242/jeb.054825. PMID:21613523.

Morrissey-McCaffrey, E., Shephard, S., Kelly, F.L., and Kelly-Quinn, M. 2019. Non-native species and lake warming negatively affect Arctic char Salvelinus alpinus abundance; deep thermal refugia facilitate co-existence. J. Fish Biol. 94(1): 5-16. doi:10.1111/jfb.13837. PMID:30315584.

Ojanguren, A.F., and Braña, F. 2004. Thermal dependence of embryonic growth and development in brown trout. J. Fish Biol. 28(2): 297-301. doi:10.1046/j.0022-1112.2003.00049.x.

Pankhurst, N.W., and Munday, P.L. 2011. Effects of climate change on fish reproduction and early life history stages. Mar. Freshw. Res. 62(9): 10151026. doi:10.1071/MF10269.

Parmesan, C. 2006. Ecological and evolutionary responses to recent climate change. Annu. Rev. Ecol. Evol. Syst. 37(1): 637-669. doi:10.1146/annurev. ecolsys.37.091305.110100.

Perry, G.M.L., Audet, C., Laplatte, B., and Bernatchez, L. 2004. Shifting patterns in genetic control at the embryo-alevin boundary in brook charr. Evolution, 58(9): 2002-2012. doi:10.1111/j.0014-3820.2004.tb00485.x. PMID:15521457.

Perry, G.M.L., Audet, C., and Bernatchez, L. 2005. Maternal genetic effects on adaptive divergence between anadromous and resident brook charr during early life history. J. Evol. Biol. 18(5): 1348-1361. doi:10.1111/j.14209101.2005.00954.x. PMID:16135130. 


\section{Pagination not final (cite DOI) / Pagination provisoire (citer le DOI)}

Piggott, J.J., Niyogi, D.K., Townsend, C.R., and Matthaei, C.D. 2015a. Multiple stressors and stream ecosystem functioning: climate warming and agricultural stressors interact to affect processing of organic matter. J. Appl. Ecol. 52(5): 1126-1134. doi:10.1111/1365-2664.12480.

Piggott, J.J., Townsend, C.R., and Matthaei, C.D. 2015b. Climate warming and agricultural stressors interact to determine stream macroinvertebrate community dynamics. Global Change Biol. 21(5): 1887-1906. doi:10.1111/ gcb.12861. PMID:25581853.

Polymeropoulos, E.T., Elliott, N.G., and Frappell, P.B. 2016. The maternal effect of differences in egg size influence metabolic rate and hypoxia induced hatching in Atlantic salmon eggs: implications for respiratory gas exchange across the egg capsule. Can. J. Fish. Aquat. Sci. 73(8): 11731181. doi:10.1139/cjfas-2015-0358.

Räsänen, K., Laurila, A., and Merilä, J. 2005. Maternal investment in egg size: environment- and population-specific effects on offspring performance. Oecologia, 142(4): 546-553. doi:10.1007/s00442-004-1762-5. PMID:15688215.

$\mathrm{R}$ Core Team. 2019. R: a language and environment for statistical computing. R Foundation for Statistical Computing, Vienna, Austria. Available from http://www.R-project.org.

Régnier, T., Bolliet, V., Gaudin, P., and Labonne, J. 2012. Female effects on offspring energetic status and consequences on early development in yolk feeding brown trout (Salmo trutta). J. Exp. Zool. Part A, Ecol. Genet. Physiol. 317(6): 347-358. doi:10.1002/jez.1728. PMID:22777730.

Reid, A.J., Carlson, A.K., Creed, I.F., Eliason, E.J., Gell, P.A., Johnson, P.T.J., et al. 2018. Emerging threats and persistent conservation challenges for freshwater biodiversity. Biol. Rev. 94: 849-873. doi:10.1111/brv.12480. PMID: 30467930

Rombough, P.J. 1988. Growth, aerobic metabolism, and dissolved oxygen requirements of embryos and alevins of steelhead, Salmo gairdneri. Can. J. Zool. 66(3): 651-660. doi:10.1139/z88-097.

Sæther, B.S., Siikavuopio, S.I., and Jobling, M. 2016. Environmental conditions required for intensive farming of Arctic charr (Salvelinus alpinus (L.)). Hydrobiologia, 783(1): 347-359. doi:10.1007/s10750-015-2572-y.

Salmaso, N., Anneville, O., and Straile, D. 2018. European large perialpine lakes under anthropogenic pressures and climate change: present status, research gaps and future challenges. Hydrobiologia, 824: 1-32. doi:10.1007| s10750-018-3758-X.

Savary, R., Dufresnes, C., Champigneulle, A., Caudron, A., Dubey, S., Perrin, N., and Fumagalli, L. 2017. Stocking activities for the Arctic charr in Lake Geneva: genetic effects in space and time. Ecol. Evol. 7: 5201-5211. doi:10.1002/ ece3.3073. PMID:28770060.

Sear, D.A., Pattison, I., Collins, A.L., Newson, M.D., Jones, J.I., Naden, P.S., and Carling, P.A. 2014. Factors controlling the temporal variability in dissolved oxygen regime of salmon spawning gravels. Hydrol. Process. 28(1): 86-103. doi:10.1002/hyp.9565.

Sear, D.A., Jones, J.I., Collins, A.L., Hulin, A., Burke, N., Bateman, S., et al. 2016. Does fine sediment source as well as quantity affect salmonid embryo mortality and development? Sci. Total Environ. 541: 957-968. doi:10.1016/j.scitotenv.2015.09.155. PMID:26473698.

Shrimpton, J.M., Zydlewski, J.D., and Heath, J.W. 2007. Effect of daily oscillation in temperature and increased suspended sediment on growth and smolting in juvenile chinook salmon, Oncorhynchus tshawytscha. Aquaculture, 273(2-3): 269-276. doi:10.1016/j.aquaculture.2007.10.009.

Stearns, S.C. 1992. The evolution of life histories. Oxford University Press, London. John Wiley \& Sons, Ltd. (10.1111). doi:10.1046/j.1420-9101.1993.6020304.x.

Sternecker, K., Cowley, D.E., and Geist, J. 2013. Factors influencing the success of salmonid egg development in river substratum. Ecol. Freshw. Fish. 22(2): 322-333. doi:10.1111/eff.12020.

Storm, M.A., and Angilletta, M.J. 2007. Rapid assimilation of yolk enhances growth and development of lizard embryos from a cold environment. J. Exp. Biol. 210(19): 3415-3421. doi:10.1242/jeb.005652. PMID:17872995.

Suttle, K.B., Power, M.E., Levine, J.M., and McNeely, C. 2004. How fine sediment in riverbeds impairs growth. Ecol. Appl. 14(4): 969-974. doi:10.1890/ 03-5190.

Swift, D. 1965. Effect of temperature on mortality and rate of development of the eggs of the windermere charr (Salvelinus alpinus). J. Fish. Res. Bd. Can. 22(4): 913-917. doi:10.1139/f65-086.

Teletchea, F., and Fontaine, P. 2010. Comparison of early life-stage strategies in temperate freshwater fish species: trade-offs are directed towards first feeding of larvae in spring and early summer. J. Fish Biol. 77(1): 257-278. doi:10.1111/j.1095-8649.2010.02689.x. PMID:20646151.

Thompson, R., Kamenik, C., and Schmidt, R. 2005. Ultra-sensitive Alpine lakes and climate change. J. Limnol. 64(2): 139-152. doi:10.4081/jlimnol.2005.139.

Townsend, C.R., Uhlmann, S.S., and Matthaei, C.D. 2008. Individual and combined responses of stream ecosystems to multiple stressors. J. Appl. Ecol. 45: 1810-1819. doi:10.1111/j.1365-2664.2008.01548.x.

Valdimarsson, S.K., Skulason, S., and Snorrason, S.S. 2002. The relationship between egg size and the rate of early development in Arctic charr, Salvelinus alpinus. Environ. Biol. Fishes, 65(4): 463-468. doi:10.1023/A:1021107712866.

Wallace, J.C., and Aasjord, D. 1984. The initial feeding of Arctic charr. Aquaculture, 38(5): 19-33. Available from http://www.ncbi.nlm.nih.gov/pubmed/ 19058684.

Wedekind, C., and Müller, R. 2005. Risk-induced early hatching in salmonids. Ecology, 86(9): 2525-2529. doi:10.1890/04-1738.

Wilkins, L.G.E., Clark, E.S., Farinelli, L., Wedekind, C., and Fumagalli, L. 2015. Embryonic gene expression of Coregonus palaea (whitefish) under pathogen stress as analyzed by high-throughput RNA-sequencing. Fish Shellfish Immunol. 47(1): 130-140. doi:10.1016/j.fsi.2015.08.035. PMID:26340848.

Winfield, I.J., Berry, R., and Iddon, H. 2018. The cultural importance and international recognition of the Arctic charr Salvelinus alpinus populations of Windermere, UK. Hydrobiologia, 840: 11-19. doi:10.1007/s10750-0183814-6.

Wood, A.T., Clark, T.D., Andrewartha, S.J., Elliott, N.G., and Frappell, P.B. 2017. Developmental hypoxia has negligible effects on long-term hypoxia tolerance and aerobic metabolism of Atlantic salmon (Salmo salar). Physiol. Biochem. Zool. 90(4): 494-501. doi:10.1086/692250. PMID:28459654.

Yekutieli, D., and Benjamini, Y. 2001. The control of the false discovery rate in multiple testing under dependency. Ann. Stat. 29(4): 1165-1188. doi:10.1214/ aos/1013699998.

Zuo, W., Moses, M.E., West, G.B., Hou, C., and Brown, J.H. 2012. A general model for effects of temperature on ectotherm ontogenetic growth and development. Proc. R. Soc. B Biol. Sci. 279(1734): 1840-1846. doi:10.1098/ rspb.2011.2000. PMID:22130604 